\title{
Gingival compound resin and feldspar ceramic: shear strength of different adhesion systems and surface treatment
}

\begin{abstract}
The aim of this study is to assess the shear strength between gingival compound resin Amarilis Gingiva (Voco, Germany) and a feldspar ceramic Creation (Willi Geller International, Austria) at the bond surface. To this end, the test considers two adhesive systems: Adper Scotchbond $\square$ Multi-Purpose Plus, (3M ESPE, USA) and Adper Single Bond $\square$ Plus (3M ESPES, USA), and two surface treatments: with and without aluminum oxide $50 \mu \mathrm{m}$ blasting. The specimens were distributed among four groups: G1 (blasting and Scotch Bond Multipurpose); G2 (without blasting and scotch Bond Multipurpose); G3 (blasting and Adper Single bond); G4 (without blasting and Adper Single Bond). The blocks with the ceramic were primed with hydrofluoric acid at $10 \%$ and the compound resin was applied. The test specimens were subjected to thermal cycling for 5,000 cycles at $5^{\circ} \mathrm{C}$, $37.5^{\circ} \mathrm{C}$ and $55^{\circ} \mathrm{C}$, and then tested for shear strength. Data were organized in a spreadsheet and analyzed with one-way ANOVA and Tukey's test. Here, treatment of the ceramic surface with blasting results in significant higher shear strength, regardless of adhesive type. Among the specimens submitted to blasting, the association of the adhesive 3M ESPE Adper Scotchbond $\square$ Multi-Purpose Plus resulted in significantly higher shear strength.
\end{abstract}

Volume 10 Issue 3 - 2019

\section{Gilmar Gil Godoy, Gisseli Bertozzi Ávila, Aline Batista Gonçalves Franco, Amanda Gonçalves Franco, Geraldo Alberto Pinheiro De Carvalho, Sérgio Candido Dias \\ Department of Restorative Dentistry, São Leopoldo Mandic} Research Institute, Brazil

Correspondence: Amanda Gonçalves Franco, Department of Restorative Dentistry, São Leopoldo Mandic Research Institute, Brazil,Tel 5537999650164, Email amandagfranco38@gmail.com

Received: May 14, 2019| Published: May 20, 2019

Keywords: composite resin gum, feldspathic ceramics, hydrofluoric acid

\section{Introduction}

The influence of aesthetics on the various dentistry specialties is increasingly more relevant. Areas that historically have focused on treatments to restore oral health are currently driven to seek solutions to aesthetic interventions. Also, different specialties have sought to interact with the aim of achieving better aesthetic outcomes. Currently, the relationship between prosthesis and periodontics overcomes the need of rehabilitation and maintenance of periodontal health. The restoration procedures are significantly hindered in situations such as loss of soft and bone tissue that cause the appearance of defects, mainly in the anterior region, when surgical interventions are not possible. In these cases, dentogingival prosthetic restoration is a viable alternative for the aesthetic and functional restoring., Current ceramics used in dentogingival prostheses are known to be aesthetically fit since they simulate the natural color of teeth and have adequate physical properties. However, the ceramics that simulate gingival color offer a less than optimal result. The alternative choice, with a better pink aesthetic, is the gingival color compound resin. This material, however, raises questions regarding bond strength with porcelain infrastructures. ${ }^{3-5}$ The concept of adhesion has changed the dental practice, placing adhesive dentistry in constant evolution. New and improved products are constantly being introduced to the market, motivating research to unveil and compare behaviors under different conditions. However, mechanical, chemical and mechanicalchemical methods are still designed to promote an adequate irregular surface and optimize mechanical retention of the resin. The ceramic surface can be treated with acids, ${ }^{6,7}$ or with diamond-tipped burs and blasting. ${ }^{89}$ Given this context, the aim of this study is to analyze the bond strength between feldspar ceramic Creation (Willi Geller International $\mathrm{GmbH}$, Meiningen - Austria) and the gingival compound resin Amaris Gingiva (Voco, GmbH, Cuxhaven, Germany) using shear strength testing and thermal cycling. The analysis will consider two adhesive bond agents: 3M ESPE Adper Single Bond $\square$ Plus and
3M ESPE Adper Scotchbond $\square$ Multi-Purpose Plus with or without surface treatment (blasting with aluminum oxide of $50 \mu \mathrm{m}$ ).

\section{Proposition}

The objective of this study is to assess the bond strength between feldspar cermic Creation (Willi Geller InternationalGmbH, Meiningen - Austria) and gingival compound resin Amaris Gingiva (Voco, $\mathrm{GmbH}$, Cuxhaven, Germany) using shear strength testing and thermal cycling. The analysis will consider two adhesive bonding agents: 3M ESPE Adper Single Bond Plus and 3M ESPE AdperScotchbond $\square$ MultiPurpose Plus, with or without surface treatment (blasting with aluminum oxide of $50 \mu \mathrm{m})$.

\section{Materials and methods}

This study was approved by the Research Ethics Committee of the Dentistry School and Research Center São Leopoldo Mandic, under protocol 2015/0391. To manufacture the porcelain samples, feldspar porcelain powder Creation (Willi Geller InternationalGmbH, Meiningen, Austria) was mixed with distilled water and stored in a metallic matrix with hole of $9.0 \times 4.0 \mathrm{~mm}$. For the insertion, a 24 Duflex spatula (SS White, Rio de Janeiro, Brazil) was used. 120 porcelain tablets were manufactured $(9.0 \times 4.0 \mathrm{~mm})$. They were taken out of the matrix and taken to the porcelain oven Vulcano Platiniun (EDG, São Carlos, Brazil) at a temperature of $600^{\circ} \mathrm{C}$ for 6 minutes, with heating speed of $55^{\circ} \mathrm{C} / \mathrm{min}$, under vacuum. Once reaching $910^{\circ} \mathrm{C}$, the tablets were left for 1 minute without vacuum. The tablets were then left to cool at room temperature (Figure 1).

The ceramic tablets were included using $1 / 2$ inch PVC tubes of $15 \mathrm{~mm}$ of height (Tigre, Castro, PR, Brazil) and colorless selfpolymerizable acrylic resin Jet (Artigos Odontológicos Clássico Ltda., São Paulo, Brazil). The blocks were polished in a polishing machine (Politriz, Arotec, Cotia, SP, Brazil) using water sandpaper Aquaflex (Norton, Guarulhos, Brazil) with grit sizes of 320, 400, 600, 
800,1200 and 1500 for 30 seconds each at a speed of 300rpm. The ceramic blocks were randomly distributed among four groups $(\mathrm{n}=30)$.

1. G1 - Blasting with aluminum oxide of $50 \mu \mathrm{m}$ for 10 seconds; cleaning with absolute alcohol; priming with $10 \%$ hydrofluoric acid for 4 minutes; use of adhesive AdperScotchbondMultiPurpose Plus (3M ESPE); application of gingival compound resin (AmarilisGingiva, Voco, GmbH, Cuxhaven, Germany).

2. G2-Cleaning with absolutealcohol; priming with $10 \%$ hydrofluoric acid for 4 minutes; use of adhesive AdperScotchbond $\square$ MultiPurpose Plus, (3M ESPE St Paul, MN - USA); application of gingival compound resin (AmarilisGingiva, Voco, $\mathrm{GmbH}$, Cuxhaven, Germany).

3. G3 - Blasting with aluminum oxide of $50 \mu \mathrm{m}$ for 10 seconds; cleaning with absolute alcohol; priming with $10 \%$ hydrofluoric acid for 4 minutes; use of adhesive Adper Single Bond $\square$ Plus (3M ESPESt Paul, MN - USA); application of gingival compound resin (AmarilisGingiva, Voco, $\mathrm{GmbH}$, Cuxhaven, Germany).

4. G4 - Cleaning with absolute alcohol; priming with $10 \%$ hydrofluoric acid for 4 minutes; use of adhesive 3M ESPE Adper Single Bond $\square$, (3M ESPE St Paul, MN - USA); application of gingival compound resin (AmarilisGingiva, Voco, $\mathrm{GmbH}$, Cuxhaven, Germany).

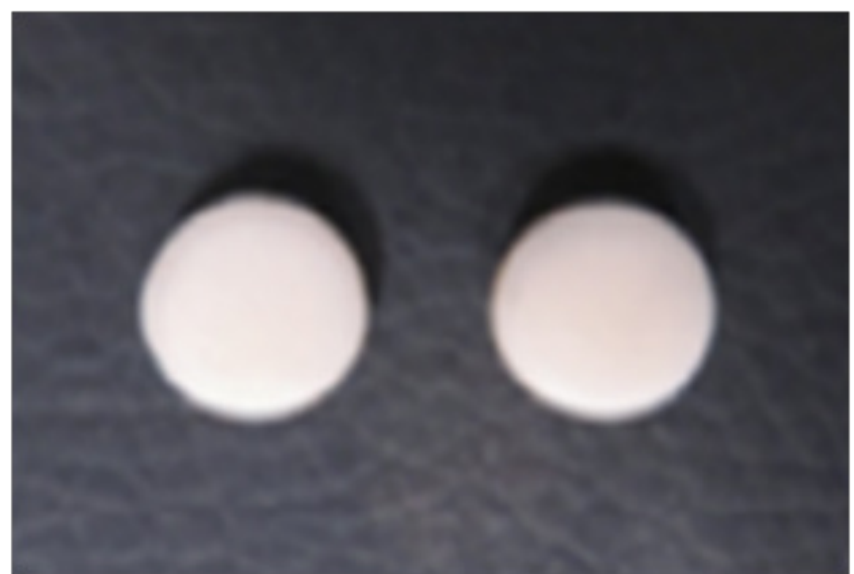

Figure I Porcelain tablets.

Following the surface treatment, the compound resin AmarilisGingiva, (Voco, GmbH, Cuxhaven, Germany) was inserted. In order to standardize the samples, a bipartite Teflon matrix with central hole of $5.0 \mathrm{~mm}$ of diameter and thickness of $3.0 \mathrm{~mm}$ was used. A portion of resin was placed over the central hole, and the piece was weighted on a precision scale $(0.0001 \mathrm{~g})$ model BL $210 \mathrm{~S}$ (Sartorius, Gottingen, Germany). Photoactivation was carried for 40 seconds with photopolymerizer EliparFree Light (3M-ESPE, Seefeld, Germany) (Figure 2). Once the specimens were manufactured, they were subjected to thermal cycling in a cycling simulator machine MSCT-3 PLUS (Marcelo Nucci-ME, São Carlos, SP, Brazil) using 5,000 cycles at $5{ }^{\circ} \mathrm{C}, 37,5{ }^{\circ} \mathrm{C}$ and $55^{\circ} \mathrm{C}$. Shear strength test was conducted using a universal testing machine EMIC DL2000 (EMIC, São Paulo, Brazil), with load cell of $50 \mathrm{KN}$ and actuator speed of 0.5 $\mathrm{mm}$ per minute (Figure 3). Results were registered in Mpa. Data were organized in a spreadsheet and submitted to D'Agostino normality test followed by one-way ANOVA and Tukey's test, using the software BioEstat version 3.0.
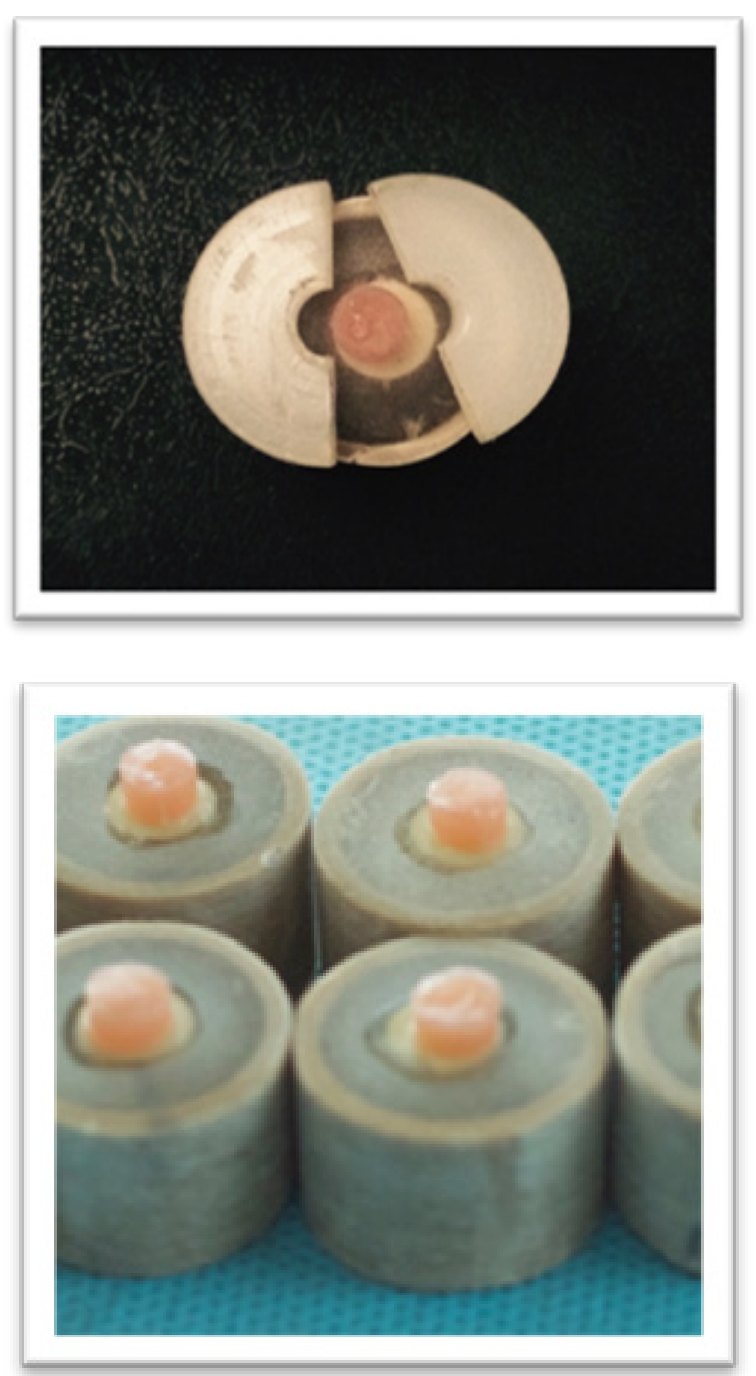

Figure 2 Teflon matrix and test specimen.

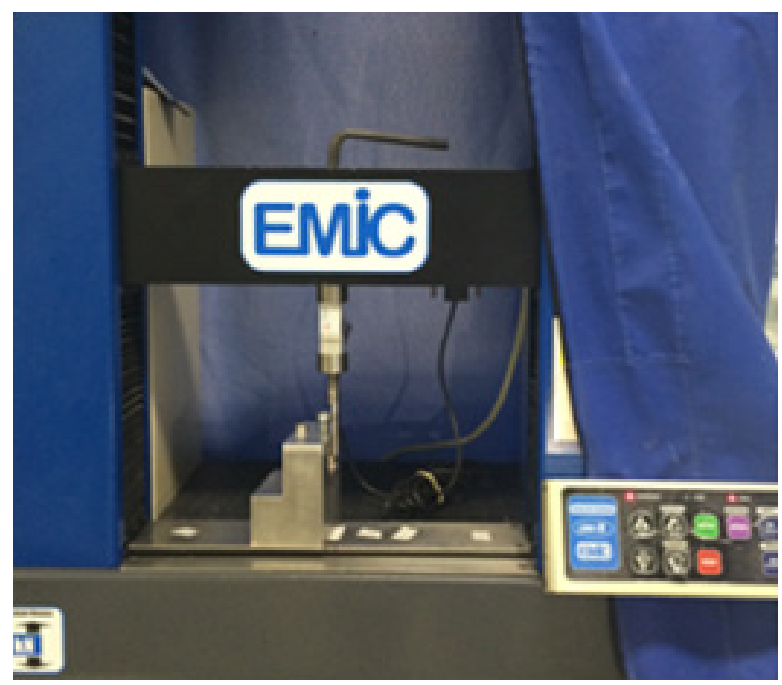

Figure 3 Shear mechanical test. 


\section{Results}

Table 1 shows mean value and standard deviation of bond strength and shear strength of groups G1-G4. Two way-ANOVA showed significant interaction between surface treatments and adhesives ( $\mathrm{p}=0.003$ ), with test power of $84.6 \%$. Tukey's test showed shear strength significantly higher for ceramic surface submitted to aluminum oxide blasting, regardless of adhesive type. Among these groups, higher results were obtained with the use of adhesive $3 \mathrm{M}$ ESPE AdperScotchbond $\square$ Multi-Purpose Plus. Among the groups not submitted to blasting, the adhesive type had no effect on bond strength (Figure 4).

Table I Mean and standard deviation of shear strength (in $\mathrm{MPa}$ ) between gingival compound resin and feldspar ceramic, organized by type of surface treatment and adhesive.

Surface treatment

\begin{tabular}{lll} 
Adhesive & & \\
\cline { 2 - 3 } & Blasting + hydrofluoric acid & Hydrofluoric \\
\hline AdperScotchbond Multi-Purpose Plus & $\mathrm{I}$ I.9I (3.,37) Aa & $6.45(3.36) \mathrm{Ba}$ \\
Adper Single Bond Plus & $7.23(2.43) \mathrm{Ab}$ & $5.14(2.46) \mathrm{Ba}$
\end{tabular}

Surface treatment

Adhesive

Blasting + hydrofluoric acid

I I.9| (3.37) $\mathrm{Aa}$

7.23 (2.43) Ab

\section{Hydrofluoric acid}

6.45 (3.36) Ba

Adper Single Bond Plus

5.14 (2.46) Ba

Caption: Mean followed by different capital letters indicates significant difference between surface treatments, considering each adhesive separately. Mean followed by small letters indicate significant difference between adhesive type, considering each surface treatment separately.

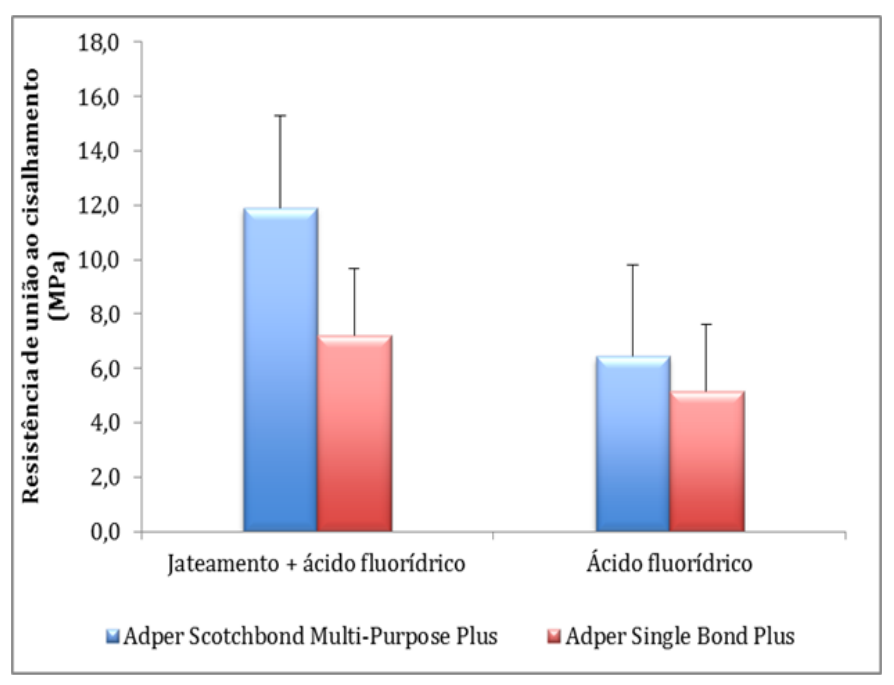

Figure 4 Bar graph showing shear strength between gingival compound resin and feldspar ceramic, according to surface treatment and adhesive.

Caption:Vertical bars represent standard deviation.

\section{Discussion}

Dental ceramics is considered an excellent material for the reproduction of natural teeth due to its aesthetical and mechanical properties. However, some clinical situations require the use of compound resin on the ceramic to restore aesthetics and function..$^{3-5,10}$
Techniques and methods have been proposed in the literature aiming to achieve better adherence to porcelain. According to some authors, priming of ceramic surface is key to a durable bond between the materials. ${ }^{11}$ Several authors have attested the improvement in adhesion with acid surface treatment. ${ }^{67,12-15}$ According to some authors, priming with hydrofluoric acid and silane, regardless of silanization protocol used, results in no significant effect on bond strength in comparison with no silane application. ${ }^{5}$ Some authors report no satisfactory results when priming with hydrofluoric acid and silane are used separately. ${ }^{16}$ Berry et al., ${ }^{17}$ on the other hand, report significant increase in bond strength of porcelain/compound resin with time of priming, and that this bond is mainly chemically induced rather than mechanically. The authors also claim that the oral environment would not reduce bond strength, in agreement with Vanderlei et al. ${ }^{18}$ According to Lacy et al., ${ }^{19}$ bond strength between resin and porcelain is given by a combination of chemical and mechanical priming. Della Bona et al., ${ }^{20}$ added the adhesive wettability as a relevant factor to increase bond strength between ceramic and resin. The cited literature was the basis for the use of $10 \%$ hydrofluoric acid for 4 minutes in all groups in this study. In addition to the acid priming, diamond-tipped burs or blasting that create an irregular surface also yield good results for the optimization of porcelain/resin adherence by fostering the mechanical retention of resin. ${ }^{89}$ According to Shahverdi et al., ${ }^{21}$ blasting of surface has a lesser effect on the bonding process in comparison with the use of burs. Here, groups treated with aluminum oxide blasting showed better shear strength results, regardless of adhesive type. In this study, preparation with blasting and priming with hydrofluoric acid resulted in higher shear strength between compound resin and feldspar ceramic. This is in agreement with Shiu et al. ${ }^{11}$ and Phoenix 
\& Shen, ${ }^{22}$ that claim that mechanical and chemical treatment of the feldspar porcelain surface produce an increase in surface area and surface energy, leading to a change in topography, which, in turn, is responsible for the increase in bond strength. The use of the adhesive 3M ESPE AdperScotchbond $\square$ Multi-Purpose Plus (11.91MPa) along with the treatment of the ceramic surface with aluminum oxide blasting resulted in significant improvement of the bond between compound resin and ceramic in comparison with the group using the adhesive 3M ESPE Adper Single Bond $\square$ Plus (7.23Mpa). On the other hand, this difference was not observed between the groups without treatment with aluminum oxide blasting. This is in agreement with authors that advocate for the association of surface treatment and adhesive agents for better results. ${ }^{23}$ Further studies might contribute with relevant information on this issue and provide recommendations on safe and effective materials and methods.

\section{Conclusion}

According to this study, it is possible to conclude that:

The ceramic surface submitted to aluminum oxide $50 \mu \mathrm{m}$ blasting followed by cleaning with alcohol and priming with hydrofluoric acid at $10 \%$ showed significantly higher shear strength, regardless of adhesive type; Between the groups submitted to blasting, the use of 3M ESPE AdperScotchbond $\square$ Multi-Purpose Plus showed better results in comparison with 3M ESPE Adper Single Bond $\square$ Plus; Without blasting, the type of adhesive showed no influence on bond strength results.

\section{Acknowledgments}

None.

\section{Conflicts of interest}

The authors declare that there is no conflict of interest.

\section{References}

1. Coachman C, Salama M, Garber D, et al. Prosthetic gingival reconstruction in a fixed partial restoration. Part 1: introduction to artificial gingiva as an alternative therapy. Int J Periodontics Restorative Dent. 2009;29(5):471-477.

2. Salama M, Coachman C, Garber D, et al. Prosthetic gingival reconstruction in the fixed partial restoration. Part 2: diagnosis and treatment planning. Int J Periodontics Restorative Dent. 2009;29(6):573-581.

3. Gourav R, Ariga P, Jain AR, et al. Effect of four different surface treatments on shear bond strength of three porcelain repair systems: An in vitro study. J Conserv Dent. 2013;16:208-212.

4. Kocaağaoğlu HH. Repair of porcelain restorations: four case reports. Eur J Prosthodont. 2015;3(2):42-46.

5. Dos Santos TCV, de Carvalho GAP, Kreve S, et al. Ceramicrepairswithresins: silanizationprotocols. J Dent Health Oral Disord Ther. 2018;9(6):451-454.
6. Abd Wahab MH, Bakar WZ, Husein A. Different surface preparation techniques of porcelain repaired with composite resin and fracture resistance. J Conserv Dent. 2011;14(4):387-390.

7. Valian A, Moravej-Salehi E. Surface treatment of feldspathic porcelain: scanning electron microscopy analysis. J Adv Prosthodont. 2014;6(5):387-394

8. Bagis B, Ustaomer S, Lassila LV, et al. Provisional repair of a zirconia fixed partial denture with fibre-reinforced restorative composite: a clinical report. J Can Dent Assoc. 2009;75(2):133-137.

9. Neis CA, Albuquerque NL, Albuquerque Ide S, et al. Surface treatments for repair of feldspathic, leucite - and lithium disilicate-reinforced glass ceramics using composite resin. Braz Dent J. 2015;26(2):152-155.

10. Raposo LH, Neiva NA, Silva GR, et al. Ceramic restoration repair: report of two cases. J Appl Oral Sci. 2009;17(2):140-144.

11. Shiu P, Souza-Zaroni WC, Eduardo CP, et al. Effect of feldspathic ceramic surface treatments on bond strength to resin cement. Photomed Laser Surg. 2007;25(4):291-296.

12. Güler AU, Yilmaz F, Yenisey M, et al. Effect of acid etching time and a self-etching adhesive on the shear bond strength of composite resin to porcelain. J Adhes Dent. 2006;8(1):21-25.

13. Naves LZ, Soares CJ, Moraes RR, et al. Surface/interface morphology and bond strength to glass ceramic etched for different periods. Oper Dent. 2010;35(4):420-427.

14. Kara HB, Ozturk AN, Aykent F, et al. The effect of different surface treatments on roughness and bond strength in low fusing ceramics. Lasers Med Sci. 2011;26(5):599-604.

15. Zogheib LV, Bona AD, Kimpara ET, et al. Effect of hydrofluoric acid etching duration on the roughness and flexural strength of a lithium disilicate-based glass ceramic. Braz Dent J. 2011;22(1):45-50.

16. Brentel AS, Ozcan M, Valandro LF, et al. Microtensile bond strength of a resin cement to feldpathic ceramic after different etching and silanization regimens in dry and aged conditions. Dent Mater. 2007;23(11):1323-1331.

17. Berry T, Barghi N, Chung K. Effect of water storage on the silanization in porcelain repair strength. J Oral Rehabil. 1999;26(6):459-463.

18. Vanderlei A, Passos SP, Özcan M, et al. Durability of adhesion between feldspathic ceramic and resin cements: effect of adhesive resin, polymerization mode of resin cement, and aging. J Prosthodont. 2013;22(3):196-202.

19. Lacy AM, La Luz J, Watanabe LG, et al. Effect of porcelain surface treatment on the bond to composite. J Prosthet Dent. 1988;60(3):288-291.

20. Della Bona A, Shen C, Anusavice KJ. Work of adhesion of resin on treated lithiadisilicate-based ceramic. Dent Mater. 2004;20(4):338-344.

21. Shahverdi S, Canay S, Sahin E, et al. Effects of different surface treatment methods on the bond strength of composite resin to porcelain. J Oral Rehabil. 1998;25(9):699-705.

22. Phoenix RD, Shen C. Characterization of treated porcelain surfaces via dynamic contact angle analysis. Int J Prosthodont. 1995;8(2):187-194.

23. Sorensen JA, Engelman MJ, Torres TJ, et al. Shear bond strength of composite resin to porcelain. Int J Prosthodont. 1991;4(1):17-23. 